\title{
Correspondence
}

\section{Needs of carers}

Sir: We agree with Cohen et al (Psychiatric Bulletin, March 1996, 20, 131-133) that the needs of informal carers are neglected and that this is an under researched area. We conducted a literature search in Medline (1985-95) and PsycLIT (1990-95) for the terms informal carers and care. We identified 118 main articles. The majority of these concerned informal carers of patients suffering from dementia. There was little information on carers of patients under the care of adult general psychiatrists.

We would like to report on our experience of liaising with informal carers of patients within our catchment area of Barnet, in outer London. All carers named by current patients of our sectorised service team (total population circa 50000 ) were sent a letter inviting them to an initial evening meeting. The meeting was organised and chaired under the joint auspices of the local branch of the Carers National Association (Ruth Pitter House, 20/25 Glasshouse Yard, London EC1A 4JS) and ourselves. Twenty-three people attended. They wanted to bypass the GP and have 24-hour direct access to the psychiatric team, reasoning that as they (the carers) had noticed a change in their relatives' mental state it might be possible to abort a full blown relapse by early treatment.

We are concerned that bypassing the primary care filter would deskill GPs, lead to unnecessary contacts with secondary services, and possibly overload these already stretched services.

The carers' group now meets each month, with at least one team member present. " Care in the Community" had neglected the needs of carers. Carers need support, advice and respite. Good communication between professional carers and informal carers without breaching medical confidentiality is important, but difficult to achieve.

\section{H. RAMPES and L. SIRELING}

Barnet General Hospital, Barnet, Herts EN5 3DJ

\section{Fighly specialised services}

Sir: Regarding the survey of highly specialised psychiatric services (Beasley et al, Psychiatric Bulletin. March 1996, 20, 129-130), I was extremely astonished to see no mention of the psychiatry of learning disability, which requires skills beyond the experience of general psychiatrists. Psychiatrists in learning disability have been providing specialised psychiatric services, including neuropsychiatry, for many years with few resources and scant recognition, developing community care successfully and earlier than colleagues in other branches of psychiatry. I look forward to when the psychiatry of learning disability will be resourced and recognised properly and when we will not have to endure the unkindest cut of non-recognition of the speciality.

\section{CHAKRABORTI}

Park View Resource Centre, King's Lynn, Norfolk PE30 5QD

Authors' reply: We have every sympathy with Dr Chakraborti's view of the importance of psychiatry of learning disabilities. However, we deliberately confined our study to those highly specialised services which are not formally and nationally recognised and necessarily provided in every locality. For this reason we did not include forensic psychiatry, the psychiatry of addiction. child and adolescent psychiatry, the psychiatry of learning disabilities, etc. which are already fully covered by Sections of the College. This distinction between the specialised and highly specialised services was identified in an earlier and related article in the Bulletin (Crisp, Psychiatric Bulletin, November 1995, 19, 657-659).

\section{J. BEASLEY \\ I. F. BROCKINGTON}

A. CRISP

University of Birmingham, Birmingham B15 $29 Z$

\section{Fitness to be interviewed?}

Sir: Protheroe \& Roney (Psychiatric Bulletin. February 1996, 20, 104-105) report the findings of their survey of senior registrars in Yorkshire concerning assessments of 'fitness to be interviewed' in police stations. Unfortunately they do not report all their findings. They cite criteria used by senior registrars to assess 'fitness to be interviewed', report that the majority had been asked to make such an assessment and comment on the lack of formal training on this matter. However, they beg the question as to whether or not it is appropriate that such a judgement should be made by senior registrars. I know that at least one of their respondents argued that it is not. 